\title{
COMPREENSÕES DE EDUCAÇÃO AMBIENTAL A PARTIR DE CHARGES DO FACEBOOK
}

\author{
UNDERSTANDINGS OF ENVIRONMENTAL EDUCATION BASED ON \\ FACEBOOK CARTOONS
}

Tamini Wyzykowski ${ }^{1}$

ORCID iD: $\underline{0000-0001-9821-2463}$

Marli Dallagnol Frison ${ }^{2}$

ORCID iD: 0000-0003-4985-1992

Vidica Bianchi ${ }^{3}$

ORCID iD: $\underline{0000-0003-0277-0191}$

\begin{abstract}
RESUMO
O presente texto discute sobre algumas contribuições que charges publicadas no Facebook podem oferecer para potencializar o desenvolvimento da Educação Ambiental (EA) no ensino de Ciências. A investigação é caracterizada como uma pesquisa qualitativa de análise de conteúdo. Para a construção de dados foram pesquisadas no Facebook charges com representações gráficas de EA, divulgadas na mídia social de modo público. O material selecionado foi classificado em três categorias: Charge de Educação Ambiental com Realidade Alterada, Charge de Educação Ambiental com Ficção Contextualizada e Charge de Educação Ambiental e Desenvolvimento Sustentável. A discussão dos resultados constituiu-se a partir do referencial teórico que trata da EA com base em autores que discorrem sobre o ensino escolar. Os resultados construídos mostram que charges que circulam no Facebook têm potencial para instigar discussões sobre EA e que, portanto, se constituem como um recurso didático favorável ao desenvolvimento da EA nos contextos escolares.
\end{abstract}

Palavras-chave: Desenvolvimento Sustentável. Ensino de Ciências. Mídia Social.

\begin{abstract}
The present text discusses contributions that cartoons published on Facebook might offer to potentialize the development of Environmental Education (EE) in Science teaching. The investigation is a qualitative research of content analysis. Facebook cartoons with graphical representations of EE published in the social media in a public manner wereused for data building. The selected materials were classified in three categories: environmental education cartoon with altered reality,

\footnotetext{
${ }^{1}$ Doutoranda em Educação nas Ciências pela Universidade Regional do Noroeste do Estado do Rio Grande do Sul (Unijuí). Bolsista da Coordenação de Aperfeiçoamento de Pessoal de Nível Superior (Capes), Ijuí, RS, Brasil. Endereço para correspondência: Rua Minas Gerais, 98, casa, bairro Santa Fé, Giruá, RS, Brasil, CEP: 98800-000. E-mail: tamini.wyzykowski@ gmail.com.

${ }^{2} \mathrm{PhD}$ pela Universidade Estadual Paulista Júlio de Mesquita Filho (Unesp) e doutora em Educação pela Universidade Federal do Rio Grande do Sul (UFRGS). Professora e pesquisadora do Programa de PósGraduação em Educação nas Ciências e do Departamento de Ciências da Vida da Universidade Regional do Noroeste do Estado do Rio Grande do Sul (Unijuí), Ijuí, RS, Brasil. Endereço para correspondência: Rua Emílio Glitz, 793, casa, Bairro Industrial, Ijuí, RS, Brasil, CEP: 98700-000. E-mail: marlif@unijui.edu.br

${ }_{3}$ Doutora em Ecologia pela Universidade Federal do Rio Grande do Sul (UFRGS). Professora e pesquisadora do Programa de Pós-Graduação em Educação nas Ciências e do Departamento de Ciências da Vida da Universidade Regional do Noroeste do Estado do Rio Grande do Sul (Unijuí), Ijuí, RS, Brasil. Endereço para correspondência: Rua Tupis, 237, casa, Bairro Pindorama, Ijuí, RS, Brasil, CEP: 987000-000. E-mail: vidica.bianchi@unijui.edu.br.
} 
environmental education cartoon with contextualized fiction, and environmental education and sustainable development cartoon. The results were discussed based on the EE theoretical reference by authors who write about school teaching. The results show that cartoons circulating on Facebook have the potential to instigate discussions about EE and, thus, constitute themselves as favorable didactic resources for the development of EE in school contexts.

Keywords: Sustainable Development. Science Teaching. Social Media.

\section{INTRODUÇÃO}

O presente trabalho visa a discutir sobre contribuições que charges podem oferecer para potencializar discussões que dizem respeito à Educação Ambiental (EA), especialmente no ensino de Ciências nos contextos escolares. Para tanto, serão problematizadas algumas charges contendo especificidades de EA, que foram socializadas publicamente na mídia social e na rede virtual denominada "Facebook".

A EA é uma temática de significativa relevância, pois pensar e cuidar do ambiente infere respeitar todas as formas de vida que o compõem. Tratando-se da EA, a escola, constituída pela humanidade e responsável pela promoção da cultura e do desenvolvimento das próximas gerações, tem uma expressiva responsabilidade e contribuição no que se refere à promoção de ações de desenvolvimento sustentável ao Planeta. Seguindo a linha de pensamento, Segura (2001, p. 165), citada por Medeiros et al. (2011, p. 7), discorre que

quando a gente fala em educação ambiental pode viajar em muitas coisas, mas a primeira coisa que se passa na cabeça do ser humano é o meio ambiente. Ele não é só o meio ambiente físico, quer dizer, o ar, a terra, a água, o solo. É também o ambiente que a gente vive - a escola, a casa, o bairro, a cidade. É o planeta de modo geral. (...) não adianta nada a gente explicar o que é efeito estufa; problemas no buraco da camada de ozônio sem antes os alunos, as pessoas perceberem a importância e a ligação que se tem com o meio ambiente, no geral, no todo e que faz parte deles. A conscientização é muito importante e isso tem a ver com a educação no sentido mais amplo da palavra. (...) conhecimento em termos de consciência (...) A gente só pode primeiro conhecer para depois aprender amar, principalmente, de respeitar o ambiente.

Essas impressões reforçam a reflexão de que é imprescindível a abordagem da EA nos contextos escolares. Nessa linha de pensamento, corroboramos com as ideias de Maldaner et al. (2007, p. 130) de que

a formação básica precisa cuidar da constituição dos sujeitos [...] tornando-os autônomos em relação ao meio social, tecnológico e natural, capazes de decidir e propor mudanças responsáveis em situações reais que, de alguma forma, se relacionam com a [...] degradação ambiental e a qualidade de vida como um todo.

Para tanto, dentre outras possibilidades, é necessário eleger e utilizar em sala de aula instrumentos de ensino capazes de intermediar a apropriação conceitual e produzir sentidos e 
significados da EA na vida dos alunos. Nessa direção, sugerimos as charges como um recurso de ensino favorável à significação da EA nas aulas de Ciências.

Vale explicitar que a charge é uma figura de linguagem que, por vezes, contém representações gráficas de EA em seu enredo. Alves, Pereira e Cabral (2013, p. 421) discutem que utilizar charges na educação escolar é uma alternativa de "suscitar nos alunos a capacidade de interpretação crítica dos fatos e assuntos veiculados nos principais meios de comunicação da atualidade, afastando-se do uso tradicional do livro didático e do quadro e giz". A problematização de charges na sala de aula pode impulsionar o pensamento crítico dos alunos sobre a EA, pois é um gênero textual que envolve humor e criatividade e é de acessível interpretação.

Ademais, usuários do Facebook, incluindo alunos e professores, podem notar que charges com representações gráficas de EA circulam assiduamente no feed desta rede virtual. Tais proposições levam a depreender que o Facebook serve de agente na promoção da EA, veiculando charges que versam sobre questões ambientais que podem ser visualizadas, interpretadas e compartilhadas por milhares de pessoas de diferentes países.

Entendemos que o professor pode fazer uso das charges que circulam no Facebook para discutir a EA em suas aulas. É nesta direção que estão voltados nosso interesse e curiosidade na tessitura deste texto. Aqui, temos o intuito de apresentar e produzir reflexões e entendimentos sobre a seguinte pergunta de pesquisa: Que contribuições charges publicadas no Facebook podem oferecer para potencializar discussões sobre questões relacionadas à Educação Ambiental?

Defendemos a importância de contestar a EA continuadamente no currículo, a fim de formarmos alunos/cidadãos críticos e comprometidos com o desenvolvimento da sociedade e da sustentabilidade do Planeta. Sauvé (2005, p. 317) enfatiza que a EA é "uma dimensão essencial da educação fundamental que diz respeito a uma esfera de interações que está na base do desenvolvimento pessoal e social: a da relação com o meio em que vivemos, com essa 'casa de vida' compartilhada". Frison e Del Pino (2012, p. 164) chamam a atenção para o importante papel que a escola desempenha, para que "a conscientização ambiental possa ser desenvolvida nas e pelas pessoas de forma que suas atitudes possibilitem intervenções responsáveis e qualificadas na sociedade".

Nessa direção, na condição de professoras de Ciências, apostamos que a problematização de charges advindas do Facebook pode ser um caminho possível para a sensibilização ambiental e o desenvolvimento da EA nos espaços escolares. 


\section{REFERENCIAL TEÓRICO}

Inicialmente, cabe demarcar que no Brasil a EA é destacada pela Constituição Federal de 1988, que determina sua discussão em todos os níveis de ensino, a fim de estimular nas pessoas a conscientização e a sensibilização sobre a importância de cuidar e preservar o ambiente (BRASIL, 1988). Os Parâmetros Curriculares Nacionais (PCNs) também mencionam a relevância de difundir a EA, especialmente quando se apresentam para debate os temas transversais nas diferentes áreas do conhecimento, como Saúde e Meio Ambiente (BRASIL, 1997). Os Parâmetros Curriculares Nacionais para o Ensino Médio (PCNEMs) apontam para um aprendizado que possibilite ao estudante "a construção de um conhecimento científico em estreita relação com as implicações tecnológicas e suas implicações ambientais, sociais, políticas e econômicas" (BRASIL, 2002, p. 87).

Em 1999 foi sancionada uma Lei brasileira que trata especificamente sobre a EA. A Lei 9.795, de 27 de abril de 1999, assim dispõe:

entende-se por educação ambiental os processos por meio dos quais o indivíduo e a coletividade constroem valores sociais, conhecimentos, habilidades, atitudes e competências voltadas para a conservação do meio ambiente, bem de uso comum do povo, essencial à sadia qualidade de vida e sua sustentabilidade (BRASIL, 1999).

De acordo com a legislação brasileira, a EA não possui um público específico, pois envolve questões do interesse de toda população; sendo assim, deve abranger espaços formais e não formais de educação. Nessa linha de pensamento, Jacobi (2003, p. 196) ressalta que "a relação entre meio ambiente e educação para a cidadania assume um papel cada vez mais desafiador, demandando a emergência de novos saberes para apreender processos sociais que se complexificam e riscos ambientais que se intensificam".

Entre os documentos que norteiam os currículos, atualmente está sendo discutida a Base Nacional Comum Curricular (BNCC) (BRASIL, 2018). Nesse documento, a EA está destacada nas seções que apresentam o Ensino Fundamental e aparece como mais um dos temas contemporâneos que afetam a vida humana em escala local, regional e global, preferencialmente de forma transversal e integradora, que devem ser incorporados aos currículos e às propostas pedagógicas das escolas. A BNCC reforça os PCNs e as Leis que regem a discussão desta temática.

No ensino de Ciências a EA pode ser impulsionada e desenvolvida a partir de diferentes recursos de ensino. Para tanto, é importante o professor reconhecer-se como autor e investigador do contexto educativo, planejando e intencionalizando suas ações pedagógicas. 
Segundo Jacobi (2003, p. 204), o “papel dos professores(as) é essencial para impulsionar as transformações de uma educação que assume um compromisso com a formação de valores de sustentabilidade, como parte de um processo coletivo". Diante disso, compreendemos que as atividades propostas de EA devem permitir a significação de conteúdos científicos escolares e sensibilizar os alunos quanto à importância de desenvolver ações sustentáveis para o Planeta. Nesse sentido, apostamos que as charges podem ser um instrumento didático viável para trabalhar a EA nas aulas de Ciências.

Alves, Pereira e Cabral (2013, p. 430) entendem que "as charges e tiras, através de suas características humorísticas e sátiras, e por que não dizer inteligentes, promovem uma visão mais crítica dos problemas vigentes na sociedade”. Sendo assim, é possível prever que partindo do uso de charges no contexto educativo podemos iniciar importantes discussões relacionadas à EA. Na concepção dos autores, as charges despertam “o interesse dos alunos e a sua capacidade de interpretação, através dos elementos ditos e não ditos, ampliando a socialização do conhecimento e o sucesso do processo de ensino e aprendizagem" (Idem).

De acordo com Cavalcanti (2012, p. 77), as charges "em termos de conteúdo, são tão ou até mais densas que outros textos opinativos, como artigos, cartas e editoriais". O autor explica que a charge "tem o objetivo de estabelecer uma opinião crítica e assim persuadir, influenciar ideologicamente o imaginário do interlocutor" (Ibidem, p. 86). Do mesmo modo, é fácil corroborar que charges com especificidades de EA são frequentemente publicadas em jornais, revistas e em ambientes virtuais, nos quais professores e alunos estão conectados, como o Facebook.

O Facebook é uma rede social utilizada por milhares de pessoas de diferentes partes do mundo. É caracterizado por ser um ambiente de interação, que se constitui "essencialmente pelos comentários a perfis, pela participação em grupos de discussão ou pelo uso de aplicações e jogos. É um espaço de encontro, partilha, discussão de ideias" (PATRÍCIO; GONÇALVES, 2010 p. 594). Entre os estudantes é comum a utilização desta mídia virtual, pois é uma rede social popular que funciona como meio de comunicação, de informação e de entretenimento.

Ademais, o Facebook também pode ser compreendido como uma ferramenta viabilizadora de ensino e de aprendizagens, capaz de apresentar conteúdos de forma dinâmica e criativa, possibilitar a apropriação de conhecimentos do meio cultural, bem como propagar e estimular a EA. Para Patrício e Gonçalves (2010, p. 598), esta mídia social pode servir 
impulsionar a construção partilhada, crítica e reflexiva de informação e conhecimento distribuídos em prol da inteligência colectiva.

Neste trabalho, apoiadas em Bastos e Chaves (2015, p. 94), “tomamos as postagens que circulam no Facebook como discursos que como tal, devem ser analisados como integrantes de um conjunto de mecanismos capazes de governar a conduta dos indivíduos". As mesmas autoras propõem que "não podemos nos furtar à discussão sobre os atravessamentos que esse tipo de mídia promove através dos discursos que veicula" (Ibidem, p. 103). Para estas autoras diferentes conteúdos, textos e imagens, que circulam no Facebook "se constituem como engrenagens fundamentais dentro do dispositivo pedagógico midiático por determinar e nos ensinar formas de ser/estar, ver/ser visto" (Idem).

É possível afirmar, então, que professores e alunos desenvolvem aprendizagens de EA a partir de ambientes virtuais - como o Facebook - sempre que possível, posto que a tecnologia está cada vez mais presente em nosso cotidiano. De acordo com Silva e Serafim (2016, p. 72), "os meios digitais têm um enorme potencial para o ensino, mas é difícil realizar esse potencial se eles são considerados apenas tecnologias e não formas de cultura e comunicação". Nesse sentido, as mesmas autoras defendem a necessidade de o professor dinamizar o ensino; "referenda-se que as tecnologias não substituem o professor, porém podem possibilitar mudanças em sua metodologia" (Ibidem, p. 73). Com isso, compreendemos a relevância de o professor aproveitar os recursos tecnológicos para fomentar a EA em sala de aula, por exemplo, transpondo informações midiáticas em conteúdos científico-escolares. Nessa linha de pensamento, Alarcão (2011, p. 33-4) assim se manifesta:

eu diria que, primeiro que tudo, os professores têm que repensar o seu papel. Se é certo que continuam a ser fontes de informação, têm de se consciencializar que são apenas uma fonte de informação, entre muitas outras. Deve, no entanto, salientar-se que o seu valor informativo tem níveis diferentes conforme o acesso que os seus alunos puderem ter a outras fontes de informação. É fundamental que os professores percebam esta diversidade. Haverá alunos que não vão precisar muito da informação substantiva dos professores, embora precisem da informação processual no sentido de a digerirem e criticarem. Porém, outros alunos necessitarão que o professor os informe sobre a substância e sobre o processo.

Entendemos que, nas escolas, é importante direcionar os alunos a se desenvolverem como sujeitos ecológicos, sensibilizados das questões ambientais e do papel ético e moral que cada um ocupa. Os estudantes necessitam apropriar-se de "um ideário ecológico [que] nada mais é, que um conjunto de ideias, aspirações, desejos e metas, construídos e desenvolvidos a todo momento da vida dos sujeitos" (MARQUES; OLIVEIRA; ROCHA, 2019, p. 94-95). O sujeito ecológico desenvolve-se ao longo da vida por meio de constantes processos de reflexão e tomadas de decisão, que implicam constituição humana e transformação social. Ele 
"toma para si uma postura de mudança individual e coletiva, em uma tendência ecológica e crítica. Ele torna-se uma referência, um modelo a ser seguido pelos demais" (Ibidem, p. 95).

Ao encontro dessas ideias, Medeiros et al. (2011, p. 3) destacam a importância de que "mais do que informações e conceitos, a escola se disponha a trabalhar com atitudes, com formação de valores e com mais ações práticas do que teóricas para que o aluno possa aprender a amar, respeitar e praticar ações voltadas à conservação ambiental". Com base nos mesmos autores e em Vigotski (2001), reiteramos que a escola é um ambiente de socialização cultural, que possibilita aos sujeitos desenvolverem seu processo de individualização.

\section{METODOLOGIA}

Esta investigação está caracterizada como uma pesquisa qualitativa de análise de conteúdo, conforme descrevem Lüdke e André (2011).

Para a construção deste trabalho, inicialmente buscamos no Facebook charges com representações gráficas de EA. A produção dos resultados ocorreu no segundo semestre de 2018. Optamos por selecionar charges divulgadas na mídia de modo público, ou seja, que poderiam ser visualizadas por qualquer pessoa inserida no meio virtual.

As charges foram coletadas no Facebook, agrupadas e analisadas. Com apoio nos estudos de Günzel, Fröhlich e Leite (2018), o material selecionado foi classificado em três categorias: (1) Charge de Educação Ambiental com Realidade Alterada; (2) Charge de Educação Ambiental com Ficção Contextualizada; e (3) Charge de Educação Ambiental e Desenvolvimento Sustentável. A discussão dos resultados constituiu-se a partir do referencial teórico da EA e com base em autores que discorrem sobre o ensino escolar.

\section{ANÁLISES E RESULTADOS}

De acordo com Alves, Pereira e Cabral (2013, p. 430), "a charge e as tiras humorísticas são recursos atrativos que o professor e o aluno devem explorar, pois, além de trabalhar a prática de leitura de texto, aumenta a leitura de mundo que estes gêneros possibilitam mediante a intertextualidade”. Em nossa investigação no Facebook identificamos charges com especificidades de EA, que podem ser utilizadas pelo professor no intuito de propor debates sobre a EA junto aos alunos nas aulas de Ciências. Logo, discutiremos as categorias EA identificadas nas charges, considerando suas representações gráficas. 


\subsection{Charge de Educação Ambiental com Realidade Alterada}

A primeira categoria - Charge de Educação Ambiental com Realidade Alterada - é composta por charges que ilustram situações que acontecem em nosso contexto social. Fazem parte deste grupo charges que apresentam circunstâncias ambientais com tom de humor e de sátira. É o que bem-expressam as Figuras 1 e 2, respectivamente.

Figura 1 - Desmatamento e crescimento econômico

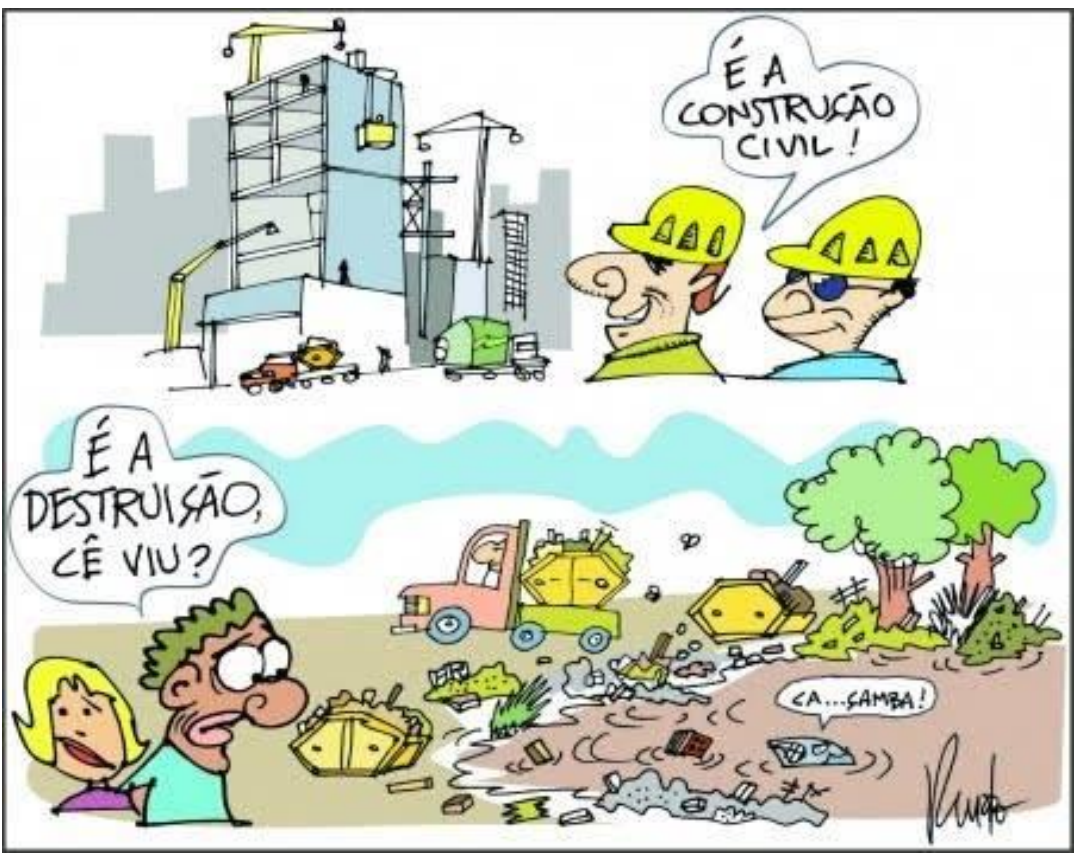

Fonte: Facebook, 2018.

Figura 2 - Descarte inadequado do lixo e seus agravantes

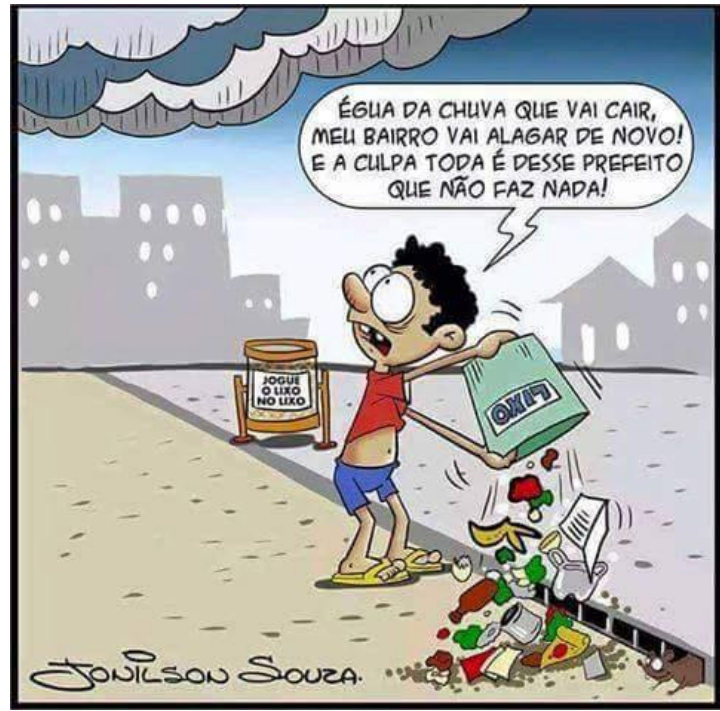

Fonte: Facebook, 2018. 
Podemos interpretar a partir das charges apresentadas que, algumas vezes, o homem percebe a existência de problemas ambientais em seu meio, mas ignora ou parece não se reconhecer como agente responsável de tais acontecimentos. Diante de situações como estas, Mucelin e Bellini (2008, p. 123) argumentam que "a ocupação humana de ambientes urbanos mais saudáveis requer do cidadão a condição de ser agente principal no processo de interação com o meio. O ser humano precisa estimular a percepção e se compreender como um constituinte da natureza e não como um ser a parte".

A charge da Figura 1 ilustra o uso insustentável do ambiente em prol do crescimento econômico. Vale refletir que o desmatamento e as queimadas são agravantes para o aquecimento global e o efeito estufa do Planeta. No Brasil, parece cada vez mais comuns áreas de florestas dando lugar ao cultivo agrícola ou à criação extensiva de bovinos. Em decorrência disso, surgem alguns agravantes, como as alterações climáticas, a extinção de espécies de plantas e de animais em razão da perda do hábitat natural, e impactos sociais, pois, conforme o ambiente é destruído, mais difícil fica o acesso aos recursos naturais que interferem na qualidade de vida das pessoas.

Outro problema ambiental preocupante é o descarte inadequado do lixo, que é denunciado na charge da Figura 2. A charge convida a pensar na proposição de que "se há necessidade de construirmos outra ética, ambientalmente guiada, também há necessidade de construirmos outra realidade social, que nos dê sustentação para pôr em prática as propostas que temos produzindo" (PODEWILS; PEDRUZZI; MINASI, 2018, p. 32). O desenvolvimento da sustentabilidade ambiental depende do engajamento responsável de toda a sociedade. O envolvimento de indústrias, entidades, órgãos públicos, comunidades e pessoas civis em geral é determinante no progresso desta causa.

Os meios de comunicação denunciam que é alarmante a quantidade de resíduos sólidos que é produzida diariamente no mundo, considerando-se que uma quantia expressiva desses rejeitos não passa por processos de tratamento e reciclagem. Entre as principais consequências decorrentes da produção e descarte incorreto do lixo, estão: o aumento da poluição, os alagamentos e inundações pela obstrução de vias públicas, danos à saúde de pessoas e animais e altos gastos de dinheiro público, necessários para administrar e controlar todas estas divergências sociais.

É presumível inferir que a raiz destes conflitos, entre homem e ambiente, está no consumo indiscriminado. Para evitar, ou, pelo menos amenizar estas situações, é preciso transformar valores culturais que, por vezes, estão fortemente estabelecidos na sociedade. Isso reforça a contínua necessidade da EA em diferentes espaços sociais. É imprescindível uma EA 
contextualizada, que desperte nas pessoas a sensibilização quanto à "responsabilidade de ser, de saber e de agir, o que implica compromisso, lucidez, autenticidade, solicitude e coragem" (SAUVÉ, 2005, p. 321).

Para contextualizar a EA nos espaços formais de educação, como sugerem Rodrigues e Kindel (2019), é importante pensar e desenvolver o currículo escolar abrangendo a problematização de temáticas socioambientais, de modo transversal e interdisciplinar. Os autores pontuam que projetos relacionados com EA na escola, como um projeto de desenvolvimento de uma horta escolar e/ou um projeto de separação de resíduos, são propostas possíveis de serem realizadas e podem envolver a participação ativa de alunos e de professores de todas áreas do conhecimento. Ao participar de projetos com esse cunho socioambiental, conforme é exposto por Rodrigues e Kindel (2019), os alunos podem desenvolver sentimentos e percepções sobre o ambiente, estabelecer relações entre as atividades propostas com suas vivências cotidianas e manifestar motivação para participação ativa durante as aulas.

\subsection{Charge de Educação Ambiental com Ficção Contextualizada}

Na segunda categoria - Charge de Educação Ambiental com Ficção Contextualizada - enquadram-se charges em que os autores recorreram à imaginação para informar os leitores sobre problemas ambientais e suas consequências para todos os ecossistemas. Nas charges apuradas acontece a personificação de animais, plantas e até mesmo do nosso Planeta, como pode ser observado na figura 3:

Figura 3 - O homem ameaça a vida de outras espécies

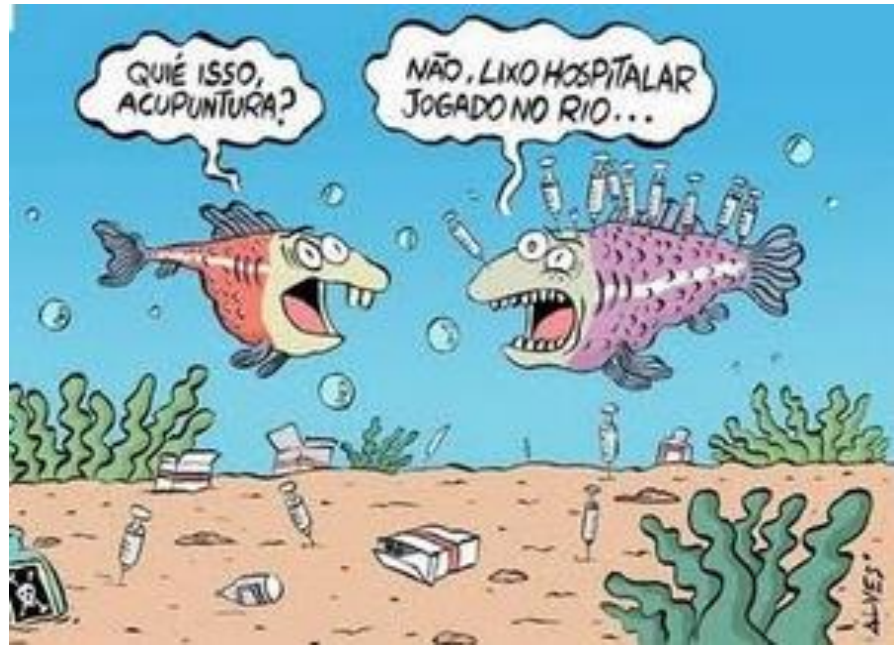

Fonte: Facebook, 2018. 
Figura 4 - A ação humana e o aquecimento do Planeta

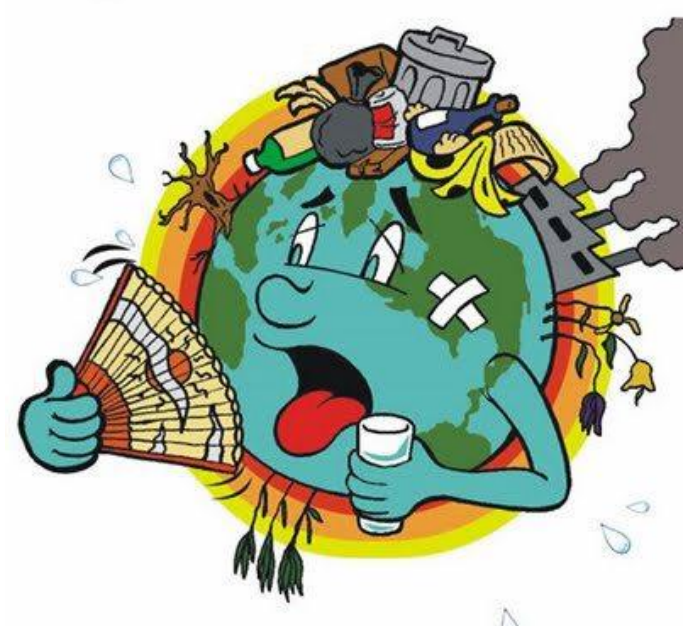

Fonte: Facebook, 2018.

Nessas Figuras - 3 e 4 - percebemos que os peixes e o Planeta estão ilustrados compondo-se de sentimentos e da capacidade da fala, assim como os humanos. Trata-se da recorrência de uma figura de linguagem - a prosopopeia -, que aparece nas charges no intuito de despertar a atenção e tornar a informação mais impactante ao leitor.

Na Figura 3 observamos que o autor ilustrou dois peixes conversando. Um deles possui alocadas em seu corpo seringas oriundas de lixo hospitalar descartado incorretamente no rio. A charge alerta que seres aquáticos, plantas e animais, corriqueiramente morrem ou têm a qualidade de vida afetada em seus ecossistemas em razão da poluição causada pelo acúmulo de lixo ou de esgoto. Vale considerar que estes organismos, assim como o homem, têm necessidade de um ambiente que proporcione condições favoráveis para o seu pleno desenvolvimento e sobrevivência.

A partir da Figura 4 captamos que o planeta Terra está pedindo socorro. A charge contém elementos que conduzem à percepção de que nosso Planeta sofre por conta da poluição causada pelo lixo e pelo esgoto em virtude do desmatamento, devido ao uso de agrotóxicos e em resposta ao efeito estufa. Estas corroborações direcionam à reflexão de que as condutas do homem refletem em todo ambiente e influenciam na qualidade de vida de diferentes organismos.

De acordo com Lopes e Albuquerque (2018 p. 159),

na última década, o Brasil expandiu em 190\% o mercado de agrotóxicos, o que colocou o País em primeiro lugar no ranking mundial de consumo desde 2008. [...] O Brasil possui, desde a década de 1970, legislações que regulamentam o registro, a produção, o uso e o comércio dessas substâncias em seu território. Além da relativa frouxidão, que marca tais processos, exemplificada pela liberação de produtos 
proibidos em diversas regiões do planeta, a grande fragilidade está na fiscalização e nas medidas adotadas para que tais legislações sejam cumpridas.

Os dados apresentados pela referida pesquisa preocupam e reforçam a relevância da EA para a sustentabilidade do planeta. No entendimento dos autores, o uso de agrotóxicos ocasiona sérios e diferentes impactos no ambiente e na saúde humana. Dentre os impactos ambientais pelo uso de agrotóxicos, o estudo bibliográfico de Lopes e Albuquerque sistematiza que as publicações produzidas no período de 2011 a 2017 “evidenciam o prejuízo causado sobre os insetos, a água, o solo e os peixes pelo uso dessas substâncias, muitas vezes, por alterarem seu habitat natural” (2018, p. 522). Ao discutir sobre os impactos na saúde humana pelo uso de agrotóxicos, a investigação analisa que não estão descartadas as possibilidades de intoxicações, distúrbios respiratórios, doenças mentais, tremores, alterações celulares, desenvolvimento de diferentes tipos de câncer e malformações congênitas nos recém-nascidos. O que mais preocupa é que "mesmo diante de tamanha exposição a doenças relacionadas aos agrotóxicos, estudos revelam que muitos agricultores não possuem a percepção desse risco e que ainda existe uma escassez de práticas chamadas de segurança e saúde no trabalho" (LOPES; ALBUQUERQUE, 2018, p. 525).

A medida que o homem prioriza seu próprio conforto e sua qualidade de vida, primando pela tecnologia e pelo crescimento econômico, por vezes não se dá por conta ou ignora que, agindo desta maneira, estabelecerá uma relação desarmônica com o ambiente. Isso caracteriza-se como uma questão controversa que precisa ser dialogada em sala de aula. Reis (2007, p. 127) chama a atenção afirmando: “[...] controvérsias deste tipo não podem ser resolvidas simplesmente numa base técnica, pois envolvem outros aspectos, tais como hierarquizações de valores, conveniências pessoais, questões financeiras, entre outras".

Uhmann e Follmann (2019) também reforçam que a escola, assim como outros contextos sociais, é propulsora na constituição dos sujeitos. Consoante as autoras, é notório que "a mídia tem influenciado constantemente no dia a dia das pessoas, o que nos instiga a trabalhar com os aspectos controversos de fundamental importância na atualidade" (UHMANN; FOLLMANN, 2019, p. 16).

Nesse sentido, a utilização de charges no ensino de Ciências é válida para impulsionar reflexões sobre questões controversas imbricadas na EA. As charges contribuem para a constituição de alunos críticos perante os fatores que interferem no desenvolvimento e na sustentabilidade do Planeta. Concordamos com Costa (2013, p. 29), que explica que "um aluno crítico é alguém capaz de pensar e agir em sociedade como verdadeiro cidadão ao invés de se fixar no conformismo". Consoante a autora, "criticar não é ser rebelde e nem ser 
pessimista, mas saber se expressar diante dos acontecimentos e não reprimir a sua opinião em prol dos outros" (Idem).

\subsection{Charge de Educação Ambiental e Desenvolvimento Sustentável}

Na terceira categoria - Charge de Educação Ambiental e Desenvolvimento Sustentável - estão agrupadas charges que destacam o homem como integrante do Planeta, assim como os outros seres vivos. São charges que orientam ações voltadas para a sustentabilidade, sensibilizando o leitor quanto a sua responsabilidade de cuidar do ambiente, conforme podemos observar na Figura 5.

Figura 5 - -(menos) EGO + (mais) ECO

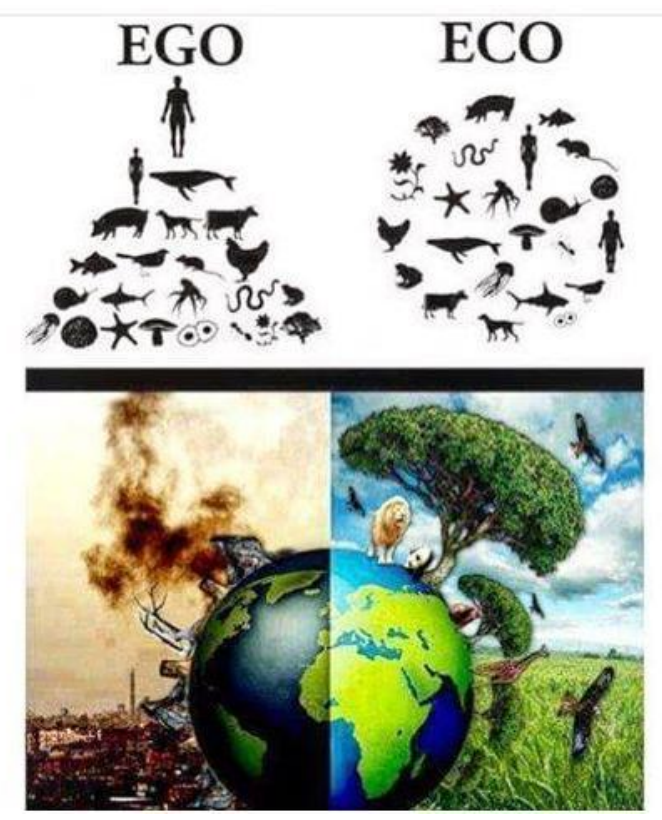

Fonte: Facebook, 2018.

Na charge que intitulamos “- (menos) EGO + (mais) ECO” presenciamos a relevância de o homem construir uma relação harmônica junto ao Planeta. Morim (2011, p. 66) defende a necessidade de as pessoas aprenderem a viver no ambiente: "precisamos doravante aprender a ser, a viver, a dividir e a comunicar como humanos do planeta Terra, não mais somente pertencer a uma cultura, mas também ser terrenos. Devemos dedicar-nos não só a dominar, mas a condicionar, a melhorar, a compreender". Isso implica "sobretudo a reconstrução do conhecimento a partir de novas visões, potencialidades e valores, guiados por novas significações e sentidos civilizatórios” (LEFF, 1998, p. 336). 
Compreendemos que é preciso uma reflexão crítica constante de que nossa espécie não é superior e nem unânime no lugar em que estamos. É nosso dever, na condição de "hóspedes da Terra", nos habituarmos à prática de atitudes conscientes, que são necessárias à sustentabilidade do ambiente e para a qualidade de vida de todos os organismos que residem no Planeta. Dentre as ações sustentáveis que podemos adotar em nosso cotidiano, destacamos: a separação e o descarte adequado do lixo, a reciclagem e a reutilização de objetos, a economia de água e de energia elétrica em nossas residências e locais de trabalho, a preferência pelo uso de transportes coletivos, o cuidado e a preservação da fauna e da flora, a diminuição do consumo de alimentos industrializados, a substituição de sacolas plásticas por sacolas ecológicas e a administração consciente e controlada do nosso dinheiro, especialmente na compra de roupas, calçados e equipamentos eletrônicos, dentre outras.

Com apoio em Costa e Loureiro (2018) mencionamos as reflexões de Paulo Freire que referem a EA, destacando a pertinência do desenvolvimento de uma EA crítica para a sustentabilidade do ambiente. Estes autores expressam que

\begin{abstract}
em nenhuma das aproximações com a EA crítica, Paulo Freire pode ser assumido de forma fragmentada e desconexa da realidade. $O$ tema central de sua reflexão para a EA crítica é a educação numa perspectiva político-social de totalidade, na ótica de um projeto global de transformação de uma nova sociedade. Igualmente, a interdisciplinaridade na EA crítica não é somente uma preocupação acadêmica. Se nos isolamos na especificidade dos diferentes campos, o real resultará fragmentado, e a totalidade enquanto pressuposto primordial do método crítico e a compreensão ontologicamente dialética da unidade sociedade-natureza se esvaziam na práxis educativa (COSTA; LOUREIRO, 2018, p. 97-98).
\end{abstract}

Ademais, como propõe Morim (2011, p. 68), “a educação do futuro deverá ensinar a ética da compreensão planetária". Junto disso, assumimos a proposição de Sato e Carvalho (2005 p. 12) de que "a EA pode ser uma preciosa oportunidade na construção de novas formas de ser, pensar e conhecer que constituem um novo campo de possibilidade de saber". Compreendemos que a EA deve ser entendida, internalizada e praticada pelas pessoas para que, de fato, ocorram transformações significativas na vida e no ambiente, e isso tudo requer compromisso e responsabilidade de todos nós.

\title{
5 CONSIDERAÇÕES
}

Os resultados construídos apontam para a necessidade de se pensar em estratégias para o pleno desenvolvimento da EA no ensino de Ciências. Foi possível identificar que charges que circulam no Facebook têm potencial para instigar profícuas discussões sobre EA, e que, 
portanto, se constituem como um recurso didático que pode ser utilizado pelo professor nas aulas de Ciências, ou até mesmo em outras disciplinas do currículo escolar.

Com isso, podemos depreender que a EA pode contribuir para o desenvolvimento sustentável do Planeta e, para tanto, é necessário a constituição de sujeitos autônomos, posicionados e críticos ante o ambiente. A escola é um espaço social determinante na constituição de um ideário ecológico crítico e contemporâneo, condizente com o contexto histórico-social e cultural da humanidade.

Nossa análise evidencia que as charges categorizadas abordam algumas problemáticas ambientais de modo contextualizado, capazes de estimular no público leitor a produção de entendimentos sobre a EA. Compreendemos que é fundamental direcionar as pessoas para uma reflexão crítica quanto à responsabilidade que cada um de nós tem perante a sustentabilidade do Planeta, pois é isso que vai viabilizar a transformação da conduta social nos contextos culturais.

Por fim, reconhecemos a relevância da EA e, na condição de professores de Ciências, assumimos que é nosso papel pensar e contribuir na formação humana mais plena e no desenvolvimento sustentável do ambiente. Isso requer o compromisso de nos identificarmos e atuarmos como educadores ambientais em nossos espaços de atuação profissional. Precisamos nos desafiar a promover práticas pedagógicas de EA que oportunizem aos estudantes a produção de sentidos e significados de EA, capazes de serem praticados, vivenciados e perpetuados culturalmente na sociedade.

\section{AGRADECIMENTOS}

O trabalho foi realizado com apoio da Coordenação de Aperfeiçoamento de Pessoal de Nível Superior - Brasil (Capes) - Código de Financiamento 001.

\section{REFERÊNCIAS}

ALACÃO, I. Professores reflexivos em uma escola reflexiva. 8. ed. São Paulo: Cortez, 2011.

ALVES, T. L. B.; PEREIRA, S. S.; CABRAL, L. N. A utilização de charges e tiras humorísticas como recurso didático-pedagógico mobilizador no processo de ensinoaprendizagem da Geografia. Educação, v. 38, n. 2, p. 417-432, maio/ago. 2013. Disponível em: https://periodicos.ufsm.br/reveducacao/article/view/7915. Acesso em: 28 nov. 2018. 
BASTOS, S. N. D.; CHAVES, S. N. O que é ser-biólogo? Com a palavra o Facebook. Alexandria - Revista de Educação em Ciência e Tecnologia, v. 8, n. 2, p. 89-106, jun. 2015. Disponível em: https://periodicos.ufsc.br/index.php/alexandria/article/viewFile/19825153.2015v8n2p89/29497. Acesso em: 29 jan. 2020.

BRASIL. Constituição da República Federativa do Brasil. 1988.

BRASIL. Secretaria de Educação Fundamental. Parâmetros Curriculares Nacionais: meio ambiente, saúde. Brasília: SEF, 1997.

BRASIL. Ministério da Educação. Secretaria de Educação Média e Tecnológica. Parâmetros Curriculares Nacionais: Ensino Médio. Brasília: MEC; Semtec, 2002.

BRASIL. Lei no 9.795 de 1999. Dispõe sobre a Educação Ambiental. Brasília, 1999.

Disponível em: http://www.planalto.gov.br/ccivil_03/LEIS/L9795.htm. Acesso em: 28 nov. 2018.

BRASIL. Ministério da Educação; Secretaria de Educação Básica; Conselho Nacional de Educação; Câmara de Educação Básica. Base Nacional Comum Curricular. Brasília: MEC, 2018.

CAVALCANTI, M. C. C. Charge: intertextualidade e humor. Revista Virtual de Letras, v. 4, n. 2, p. 73-88, ago./dez. 2012. Disponível em: http://www.revlet.com.br/artigos/155.pdf. Acesso em: 29 jan. 2020.

COSTA, F. B. Gênero charge e ensino: humor e criticidade. 2013. Monografia (Conclusão de Curso - Graduação em Letras - Português e Inglês e respectivas Literaturas) -

Universidade Estadual de Goiás, Jussara, GO, UFG, 2013. Disponível em:

http://cdn.ueg.edu.br/arquivos/jussara/conteudoN/1208/monografia-flavia_borges.pdf. Acesso em: 28 nov. 2018.

COSTA, C. A.; LOUREIRO, C. F. B. Perspectivas interdisciplinares à luz de Paulo Freire: contribuições político-pedagógicas para a Educação Ambiental Crítica. In: BATTESTIN, C.; DICKMANN, I. (Orgs.). Educação ambiental na América Latina. Chapecó: Plataforma Acadêmica, 2018. p. 77-103.

FACEBOOK. Disponível em: www.facebook.com.

FRISON, M. D.; DEL PINO, J. C. Educação ambiental como articuladora para a produção de conhecimento químico escolar: implicações no ensino e na formação para o ensino. Revista Eletrônica do Mestrado em Educação Ambiental, v. 28, p. 163-177, 2012. Disponível em: https://periodicos.furg.br/remea/article/view/3112/1783. Acesso em: 24 jan. 2020.

GÜNZEL, R. E.; FRÖHLICH, A. B.; LEITE, F. A. A utilização de charges na constituição de educadores ambientais. RELACult: Revisa Latino-Americana de Estudos em Cultura e Sociedade, v. 4, p. 1-14, 2018. Disponível em:

http://periodicos.claec.org/index.php/relacult/article/view/949/522. Acesso em: 17 jul. 2019. 
JACOBI, P. Educação ambiental, cidadania e sustentabilidade. Cadernos de Pesquisa, n. 118, p. 189-205, mar. 2003. Disponível em: http://www.scielo.br/pdf/cp/n118/16834.pdf. Acesso em: 28 nov. 2018.

LEFF, E. Saber ambiental: sustentabilidade, racionalidade, complexidade, poder. 9. ed. Petrópolis, RJ: Editora Vozes, 1998.

LOPES, C. V. A.; ALBUQUERQUE, G. S. C. Agrotóxicos e seus impactos na saúde humana e ambiental: uma revisão sistemática. Saúde Debate, v. 42, n. 117, p. 518-534, abr./jun. 2018. Disponível em: https://www.scielo.br/pdf/sdeb/v42n117/0103-1104-sdeb-42-117-0518.pdf . Acesso em: 29 abr. 2020.

LÜDKE, M.; ANDRÉ, M. E. D. A. Pesquisa em educação: abordagens qualitativas. São Paulo: EPU, 2011.

MALDANER, O. A. et al. Currículo contextualizado na área de ciências da natureza e suas tecnologias: a situação de estudo. In: ZANON, L. B.; MALDANER, O. A. (org.). Fundamentos e propostas de ensino de química para educação básica no Brasil. Ijuí: Ed. Unijuí, 2007, p. 110-138.

MARQUES T. S.; OLIVEIRA, E. M.; ROCHA, W. M. A formação de sujeitos ecológicos: um estudo do coletivo jovem de meio ambiente. Revista Reamec, Cuiabá, MT, n. 2, v. 7, p. 91108, jul./dez. 2019. Disponível em:

http://periodicoscientificos.ufmt.br/ojs/index.php/reamec/article/view/8439/pdf. Acesso em: 8 jan. 2020.

MEDEIROS, A. B. de et al. A importância da educação ambiental na escola nas séries iniciais. Revista Faculdade Montes Belos, n. 1, v. 4, p. 1-17, set. 2011. Disponível em: http://www.terrabrasilis.org.br/ecotecadigital/pdf/a-importancia-da-educacao-ambiental-naescola-nas-series-iniciais.pdf. Acesso em: 8 jan. 2020.

MORIM, E. Os sete saberes necessários à educação do futuro. 2. ed. São Paulo: Cortez; Brasília: Unesco, 2011.

MUCELIN, C. A.; BELLINI, M. Lixo e impactos ambientais perceptíveis no ecossistema urbano. Sociedade \& Natureza, n. 20, v. 1, p. 111-124, jun. 2008. Disponível em: http://www.scielo.br/pdf/sn/v20n1/a08v20n1. Acesso em: 27 dez. 2018.

PATRÍCIO, R.; GONÇALVES, V. Facebook: rede social educativa. Encontro Internacional TIC e Educação, 1. Lisboa, 2010. Disponível em: https://bibliotecadigital.ipb.pt/bitstream/10198/3584/1/118.pdf. Acesso em: 28 nov. 2018.

PODEWILS, T. L.; PEDRUZZI, A. das N.; MINASI, L. F. Uma leitura imanente de produções que versam sobre Educação Ambiental e Epistemologia. Revista Eletrônica do Mestrado em Educação Ambiental, Ed. Especial EDEA, n. 1, p. 20-34, 2018. Disponível em: https://periodicos.furg.br/remea/article/view/8560. Acesso em: 29 abr. 2020.

REIS, P. R. Os temas controversos na educação ambiental. Pesquisa em Educação Ambiental, vol. 2, n. 1, p. 125-140, 2007. Disponível em: https://www.revistas.usp.br/pea/article/view/30021/31908. Acesso em: 28 nov. 2018. 
RODRIGUES, A. P. S.; KINDEL, E. A. I. Separação de resíduos e horta como ferramentas de transformação do espaço escolar. Revista Eletrônica do Mestrado em Educação

Ambiental, v. 36, n. 1, p. 221-241, jan./abr. 2019. Disponível em:

https://periodicos.furg.br/remea/article/view/8733. Acesso em: 29 abr. 2020.

SATO, M.; CARVALHO, I. Educação ambiental: pesquisa e desafios. Porto Alegre: Artmed, 2005.

SAUVÉ, L. Educação ambiental: possibilidades e limitações. Educação e Pesquisa, v. 31. n. 2, p. 317-322, 2005. Disponível em: http://www.foar.unesp.br/Home/projetoviverbem/sauveea-possibilidades-limitacoes-meio-ambiente---tipos.pdf. Acesso em: $20 \mathrm{dez} .2018$.

SILVA, F. S.; SERAFIM, M. L. Redes sociais no processo de ensino e aprendizagem: com a palavra o adolescente. In: SOUSA, R. P. et al. (Org.). Teorias e práticas em tecnologias educacionais [on-line]. Campina Grande: EDUEPB, 2016. p. 67-98.

UHMANN, R. I. M.; FOLLMANN, L. A perspectiva do professor na Educação Ambiental. Contexto \& Educação, v. 34, n. 109, p. 9-24, set./dez. 2019. Disponível em: https://www.revistas.unijui.edu.br/index.php/contextoeducacao/article/view/7762. Acesso em: 29 abr. 2020.

VIGOTSKI, L. S. A construção do pensamento e da linguagem. São Paulo: Martins Fontes, 2001.

Submetido em: 05 de fevereiro de 2020.

Aprovado em: 05 de abril de 2020 . 